\title{
Padrões de deslocamento de bezerras de corte recebendo suplemento em pastagem de azevém
}

[Displacement patterns of beef heifers receiving supplement in Italian ryegrass pasture]

P.H. Moterle, M. G. Rocha, L. Pötter, M.J.O. Sichonany*, L.G.A. Amaral Neto, M.F. Silva, P.R. Salvador, J.M. Vicente

Universidade Federal de Santa Maria - UFSM - Santa Maria, RS

\section{RESUMO}

O objetivo deste trabalho foi avaliar o tempo de permanência, o número de bocados nas estações e o deslocamento entre estações alimentares por bezerras de corte em pastagem de azevém (Lolium multiflorum Lam.) e recebendo farelo de arroz integral como suplemento em três níveis $(0,0 ; 0,5$ e 1,0\% $\mathrm{PC})$. O método de pastejo foi rotacionado, com número variável de animais. O período de descanso foi estabelecido pela soma térmica (ST) de $187,5^{\circ} \mathrm{C}$, equivalente à ST necessária para a emissão de 1,5 folhas de azevém. O delineamento experimental foi inteiramente ao acaso, com medidas repetidas no tempo, três níveis de suplemento e seis ciclos de pastejo. O tempo de permanência em cada estação alimentar $(9,4 \mathrm{~s})$ foi semelhante para bezerras exclusivamente a pasto e as que receberam 1,0\% PC de suplemento. As bezerras que receberam $0,5 \%$ PC de suplemento permanecem $1,1 \mathrm{~s}$ a mais na estação alimentar quando comparadas com as bezerras nos demais níveis. O deslocamento entre estações alimentares (1,7 passos) e o número de bocados em cada estação alimentar (sete bocados) foram semelhantes independentemente do nível de farelo de arroz fornecido. As bezerras, ao receberem $0,5 \%$ PC de farelo de arroz, são mais dependentes da presença de lâminas foliares no estrato pastejável do dossel.

Palavras-chave: bocados por estação alimentar, farelo de arroz, número de passos entre estações alimentares, pastejo rotacionado, tempo por estação alimentar

\begin{abstract}
The aim of this study was to evaluate the length of stay and number of bites in the feeding stations and displacement between feeding stations for beef heifers on ryegrass pasture (Lolium multiflorum Lam.) and receiving rice bran as a supplement in three levels $(0.0 ; 0.5$ and $1.0 \% \mathrm{BW})$. The grazing method was rotational with variable number of animals. The interval between grazing was set by the thermal sum (TS) of $187.5^{\circ} \mathrm{C}$ equivalent to TS necessary for externalization of 1.5 leaf lamina of ryegrass. The experimental design was completely randomized with repeated measures on time, three levels of supplement and six grazing periods. The stay time at each feeding station $(9.4 \mathrm{sec}$.) was similar for heifers exclusively on pasture and receiving 1.0\% supplement BW. Heifers that received $0.5 \%$ supplement $B W$ remained $1.1 \mathrm{sec}$. longer at the feeding station than heifers on other supplement levels. Displacement between feeding stations (1.7 steps) and the number of bites in each feeding station ( 7 bites) were similar regardless of the supplied rice bran level. Heifers receiving $0.5 \%$ rice bran $B W$ are more dependent on the presence of leaf blades in grazeable stratum of canopy.
\end{abstract}

Keywords: bites per feeding station, rice bran, number of steps between feeding stations, rotational grazing, time per feeding station

Recebido em 1 de dezembro de 2016

Aceito em 3 de dezembro de 2016

*Autor para correspondência (corresponding author)

E-mail: maria_sichonan@hotmail.com 


\section{INTRODUÇÃO}

O uso de suplementos energéticos para bezerras de corte sob pastejo de espécies forrageiras de clima temperado pode ser uma estratégia para aumentar o ganho de peso individual e por unidade de área (Pötter et al., 2010). Para isso, a disponibilidade do suplemento e seu custo devem ser sempre considerados. Entre os subprodutos originados do beneficiamento dos cereais, o farelo de arroz integral pode ser utilizado como suplemento na pecuária de corte (Eloy et al., 2014).

No ambiente pastoril, o estudo do comportamento ingestivo orienta a investigação do processo de pastejo, o qual compreende os mecanismos pelos quais os animais procuram, selecionam, desfolham e ingerem a forragem. $\mathrm{O}$ entendimento do comportamento ingestivo permite inferências sobre a qualidade do ambiente pastoril e o "bem-estar nutricional" dos animais em pastejo (Carvalho et al., 2013).

Para serem eficientes no processo de forrageamento, os herbívoros desenvolveram, ao longo de sua evolução, estratégias visando otimizar o uso do tempo na busca e na colheita da forragem (Carvalho et al., 2013). O fornecimento de suplemento para animais em pastejo pode interferir no comportamento ingestivo desses animais (Bremm et al., 2005).

Ao iniciar o pastejo em uma determinada área, o animal realiza, inicialmente, uma avaliação visual desta e, ao ocupar uma dada estação alimentar, ele ali permanece até que o consumo de forragem diminua. Após, ele passa a deslocarse em busca de um local que lhe garanta um maior consumo de forragem (Palhano et al., 2006). Os padrões de deslocamento dos animais durante o pastejo são um componente crítico do seu repertório comportamental que afeta as despesas totais de energia, em razão da exposição a condições térmicas variáveis, da predação e da disponibilidade de alimentos (Bailey e Provenza, 2008).
Dessa forma, as regras de escolha e abandono das estações alimentares em um pasto afetam a quantidade de forragem ingerida pelo animal e a eficiência do processo de pastejo (Carvalho e Moraes, 2005). Também o tempo de permanência em cada estação alimentar está ligado à quantidade e à qualidade da forragem disponível (Bailey e Provenza, 2008).

A quantidade e o tipo de suplemento podem determinar diferentes respostas nos padrões de deslocamento dos animais ao longo das estações alimentares, onde cada sequência de apreensão ou alimentação é realizada (Sichonany et al., 2014). Este trabalho foi realizado com o objetivo de avaliar o tempo de permanência e o número de bocados na estação alimentar, bem como o deslocamento entre cada estação alimentar de bezerras de corte mantidas em pastagem de azevém e recebendo farelo de arroz integral como suplemento em três níveis $(0,0 ; 0,5$ e $1,0 \%$ $\mathrm{PC})$, e relacioná-los com os atributos estruturais do dossel forrageiro.

\section{MATERIAL E MÉTODOS}

O experimento foi conduzido de julho a outubro de 2014, em área do Departamento de Zootecnia da Universidade Federal de Santa Maria (UFSM), localizada na região fisiográfica da Depressão Central do Rio Grande do Sul, com altitude de $95 \mathrm{~m}$. A região possui clima subtropical úmido (Cfa), conforme classificação de Köppen.

O solo da área experimental é classificado como Argissolo vermelho distrófico arênico (Sistema, 2006). As características químicas do solo, em amostras coletadas de 0 a $10 \mathrm{~cm}$ de profundidade, são: $\mathrm{pH}-\mathrm{H} 2 \mathrm{O}$ : 5,3; índice SMP: 6,2; argila: 24,0\%; P: 10,4mg dm${ }^{-3} ; \mathrm{K}: 96,6 \mathrm{mg}$ $\mathrm{dm}^{-3}$; MO: 2,4\%; Al: 0,3cmolc L ${ }^{-1}$; Ca: 3,4cmolc $\mathrm{dm}^{-3}$; Mg: 2,0cmolc $\mathrm{dm}^{-3}$; saturação de bases: 64,3\%; e saturação por Al: 4,5\%. Os dados de temperatura, precipitação pluviométrica e insolação, nos meses que compreenderam o experimento e as médias históricas, foram obtidos junto à estação meteorológica da UFSM (Tab. 1). 
Tabela 1. Médias mensais e históricas de temperatura $\left({ }^{\circ} \mathrm{C}\right)$, precipitação pluviométrica $(\mathrm{mm})$ e insolação (horas) no período de julho a outubro de 2014

\begin{tabular}{ccccc}
\hline \multirow{2}{*}{ Item } & \multicolumn{5}{c}{ Meses } \\
\cline { 3 - 5 } & Julho & Agosto & Setembro & Outubro \\
\hline Médias observadas & & & & \\
\hline Temperatura média & 15,8 & 16,8 & 19,1 & 22,2 \\
Precipitação pluviométrica & 280,4 & 104,0 & 237,5 & 256,8 \\
Insolação & 176,4 & 188,5 & 134,0 & 166,7 \\
\hline Médias históricas & & & & \\
\hline Temperatura média & 14,5 & 15,3 & 16,6 & 19,5 \\
Precipitação pluviométrica & 148,6 & 137,4 & 153,6 & 145,9 \\
Insolação & 133,1 & 141,4 & 160,7 & 206,8 \\
\hline
\end{tabular}

${ }^{1}$ Médias históricas obtidas na Estação Meteorológica da UFSM.

Os sistemas alimentares foram constituídos por bezerras de corte em pastagem de azevém (Lolium multiflorum Lam.) recebendo farelo de arroz integral como suplemento energético $(0,0$; 0,5 e $1,0 \%$ do peso corporal (PC)), sob método de pastejo rotacionado. A área experimental (4,8ha) foi dividida em seis piquetes de 0,8 ha cada, os quais constituíram as unidades experimentais. Cada piquete foi subdividido em cinco parcelas de 0,16ha. Foi utilizada uma área anexa com 3,5ha, para permanência dos animais reguladores da altura do dossel. Foram utilizadas 40 bezerras Angus, com idade média inicial de oito meses e $155 \pm 28 \mathrm{~kg}$ de PC, sendo utilizadas três bezerras-teste em cada unidade experimental. A composição química do farelo de arroz integral foi: $89,7 \%$ de matéria seca (MS); 14,2\% de proteína bruta (PB); $14,7 \%$ de extrato etéreo (EE); $72,3 \%$ de nutrientes digestíveis totais (NDT) e $27,3 \%$ de fibra em detergente neutro (FDN). O farelo de arroz foi fornecido diariamente às 14 horas.

O método de pastejo utilizado foi o rotacionado, com número variável de animais para manter a altura do dossel pós-pastejo em $10 \mathrm{~cm}$, com sucessivos períodos de ocupação e descanso. $\mathrm{O}$ período de descanso foi estabelecido pela soma térmica (ST) de $187,5^{\circ} \mathrm{C}$, equivalente a ST necessária para a emissão de 1,5 folhas de azevém, considerando o filocrono de $125^{\circ} \mathrm{GD}$ (Confortin et al., 2010). Os três primeiros ciclos de pastejo foram de 20 dias (16 dias de descanso e quatro de ocupação), e os três ciclos finais de 15 dias (12 dias de descanso e três dias de ocupação). A ST foi calculada pela equação: $\mathrm{ST}=\mathrm{S}$ (Tmd $\left.-5^{\circ} \mathrm{C}\right)$, em que Tmd são as temperaturas médias diárias do período de avaliação e $5^{\circ} \mathrm{C}$ é o valor considerado como temperatura base de crescimento para as espécies de estação fria.

A massa de forragem (kg ha ${ }^{-1}$ MS) foi determinada pela seguinte fórmula: $\mathrm{MF}=\mathrm{MF} 2$ (i-1)-MF1(i). $\mathrm{D}^{-1}$, em que: $\mathrm{MF}=$ massa de forragem do período de ocupação, $\mathrm{MF} 1$ = massa de forragem pré-pastejo do ciclo de pastejo "i"; MF2 = massa de forragem pós-pastejo do ciclo de pastejo "i - 1"; $\mathrm{D}=$ dias do período de ocupação. A MF foi avaliada por meio do corte da forragem no interior de um quadro com $0,25 \mathrm{~m}^{2}$ de área, sendo este alocado em dois locais dentro da parcela cuja altura fosse representativa da altura média do dossel. A forragem proveniente dos cortes foi homogeneizada e dividida em duas subamostras, para determinação do teor de matéria seca do pasto e dos componentes botânicos e estruturais, realizados por meio da separação manual dos componentes do azevém: folha (lâmina) e colmo (bainha da folha + colmo). Após a separação botânica e secagem dos componentes estruturais, em estufa a $55^{\circ} \mathrm{C}$ por 72 horas, foi determinada a participação percentual de lâminas foliares e colmos, para se determinar a relação lâmina foliar:colmo $(\mathrm{F}: \mathrm{C})$.

A taxa de acúmulo diário de forragem $\left(\mathrm{kg} \mathrm{ha}^{-1}\right.$ $\left.\mathrm{dia}^{-1} \mathrm{MS}\right)$ foi determinada pela fórmula: TAD = (MF1(i) - MF2(i-1)). $\mathrm{D}^{-1}$, em que: TAD = taxa de acúmulo diário de forragem; MF1= massa de forragem pré-pastejo do ciclo de pastejo "i"; MF2 = massa de forragem pós-pastejo do ciclo 
de pastejo " $\mathrm{i}-1$ "; $\mathrm{D}=$ número de dias do período de intervalo entre pastejos.

As pesagens das bezerras foram realizadas no início e ao final de cada período de ocupação da pastagem. O jejum prévio de sólidos e líquidos de 12 horas foi realizado no início do primeiro ciclo e ao final do sexto ciclo de pastejo.

A taxa de lotação $\left(\mathrm{kg} \mathrm{ha}^{-1} \mathrm{PC}\right)$ foi calculada pela fórmula: $\mathrm{TL}=\left(\mathrm{N} *(\mathrm{PMt}+\mathrm{PMr}) \cdot \mathrm{A}^{-1}\right.$, em que: $\mathrm{TL}$ = taxa de lotação; $\mathrm{N}=$ número de dias que cada bezerra permaneceu na pastagem; $\mathrm{PMt}=$ peso corporal médio das bezerras-teste; $\mathrm{PMr}=$ peso das bezerras reguladoras $(\mathrm{kg})$ durante a ocupação do piquete em cada ciclo de pastejo; $\mathrm{A}=$ área de cada unidade experimental (ha).

A oferta de forragem ( $\mathrm{kg}$ MS $100^{-1} \mathrm{~kg}$ PC) foi calculada pela fórmula: $\mathrm{OF}=\left(\mathrm{MF} . \mathrm{n}^{-1}+\mathrm{TAD}\right)^{*}$ 100. $\mathrm{TL}^{-1}$, em que: $\mathrm{OF}=$ oferta de forragem; $\mathrm{MF}$ = massa de forragem média; $\mathrm{n}=$ dias do período de ocupação; TAD = taxa de acúmulo diário de forragem; $\mathrm{TL}=$ taxa de lotação do ciclo de pastejo. A oferta de lâminas foliares verdes foi obtida pela multiplicação da oferta de forragem pelo percentual médio de lâminas foliares na MF.

Para a avaliação de estrutura vertical do dossel, foram utilizados quadros com $0,25 \mathrm{~m}^{2}$ de área, sobrepostos, graduados a intervalos de $10 \mathrm{~cm}$ de altura até o topo do dossel. Foram tomados dois locais representativos da altura média do dossel, em cada unidade experimental. Foram retiradas amostras em cada estrato $(0-10 ;>10 \mathrm{~cm})$, as quais foram separadas manualmente em colmo, lâmina foliar e material morto para avaliação dos componentes estruturais do azevém, sendo os valores expressos em $\mathrm{g} \mathrm{cm}^{-3}$.

As avaliações das estações alimentares e do deslocamento das bezerras foram realizadas durante os períodos diurnos de pastejo, pela manhã e à tarde, em 28/07, 17/08, 05/09, 21/9, $07 / 10$ e $21 / 10 / 2014$. Foi observada a atividade de pastejo dos três animais-teste de cada piquete, em seis ciclos de 10 estações alimentares cada um. Uma estação alimentar foi considerada como o espaço correspondente ao pastejo, sem movimentos das patas dianteiras (Laca et al., 1992), e um passo foi definido como cada movimento das patas dianteiras. Com base nesses dados, foram calculados o tempo de permanência em cada estação alimentar e o número de passos entre estações alimentares.
Concomitantemente às observações da atividade de pastejo, foi registrado o tempo necessário para os animais realizarem 20 bocados, para cálculo do número de bocados em cada estação alimentar.

O delineamento experimental foi inteiramente ao acaso, com medidas repetidas no tempo, três níveis de suplemento e seis ciclos de pastejo. Foram utilizadas seis repetições por tratamento para as avaliações de padrão de deslocamento, em que cada animal foi considerado uma unidade experimental. Para as variáveis do pasto, o piquete foi considerado repetição, sendo duas repetições de área por tratamento. Realizou-se análise gráfica dos resíduos para se verificarem desvios de linearidade. Os dados foram analisados por meio do procedimento MIXED do SAS, versão 9.2 (2009). Foi realizado um teste de seleção de estruturas, utilizando-se o critério de informação bayesiano (BIC), para se determinar o modelo que melhor representasse os dados. A interação entre tratamento e ciclos de avaliação foi desdobrada quando significativa a 5\% de probabilidade. Quando observadas diferenças, as médias entre tratamento e ciclos de avaliação foram comparadas utilizando-se o recurso lsmeans, com nível de significância de $5 \%$. As médias foram submetidas ao estudo de correlação de Pearson. Na análise de regressão múltipla, para identificar as variáveis independentes com influência sobre as variáveis de resposta, foi utilizado o procedimento stepwise. Foram obtidas todas as equações possíveis, e uma foi selecionada de acordo com os seguintes critérios: menor valor de $\mathrm{P}$, menor variância residual, maior coeficiente de determinação e menor número de variáveis independentes.

\section{RESULTADOS E DISCUSSÃO}

Não houve interação entre os níveis de suplemento $\times$ ciclos de pastejo para as variáveis: massa de forragem, oferta de forragem, relação lamina foliar:colmo, taxa de lotação, altura do dossel por ocasião da entrada e saída dos animais e no dia da avaliação dos padrões de deslocamento $(\mathrm{P}>0,05)$. A altura do dossel póspastejo foi mantida em $11,5 \mathrm{~cm}$ e semelhante $(\mathrm{P}=0,5004)$, independentemente do nível de farelo de arroz fornecido aos animais, estando de acordo com o protocolo experimental. As bezerras, independentemente do nível de farelo 
de arroz fornecido, foram mantidas em semelhante massa de forragem $\left(1973,8 \mathrm{~kg} \mathrm{ha}^{-1}\right.$ MS). Conforme Roman et al. (2007), a massa de forragem em azevém deve ser mantida entre 1.100 e $1.800 \mathrm{~kg} \mathrm{ha}^{-1} \mathrm{MS}$, a qual possibilita similar eficiência de transformação da forragem em produto animal. Esse manejo ocasionou semelhante relação lamina foliar:colmo $(1,6)$. A oferta de forragem, quando as bezerras foram mantidas exclusivamente em pastejo, foi $37,7 \%$ maior quando comparado às bezerras que receberam 1,0\% PC de suplemento. Quando fornecido $0,5 \%$ PC de suplemento, a oferta de forragem foi intermediária aos demais níveis de suplemento (Tab. 2).

Tabela 2. Características estruturais e qualitativas do azevém pastejado por bezerras de corte recebendo diferentes níveis de farelo de arroz

\begin{tabular}{lcccc}
\hline \multirow{2}{*}{ Variável } & \multicolumn{3}{c}{ Níveis de suplemento (\% PC) } & \multirow{2}{*}{$\mathrm{P}^{*}$} \\
\cline { 2 - 3 } & $0,0^{1}$ & $0,5^{2}$ & $1,0^{3}$ & \\
\hline Massa de forragem $^{4}$ & $2041,2 \mathrm{a}$ & $2009,4 \mathrm{a}$ & $1870,9 \mathrm{a}$ & 0,1929 \\
& $\pm 67,40$ & $\pm 67,40$ & $\pm 67,40$ & \\
Oferta de Forragem $^{5}$ & $7,5 \mathrm{a}$ & $6,5 \mathrm{~b}$ & $5,4 \mathrm{c}$ & 0,0004 \\
& $\pm 0,29$ & $\pm 0,29$ & $\pm 0,29$ & \\
Altura do dossel pré-pastejo $^{6}$ & $23,4 \mathrm{a}$ & $22,2 \mathrm{~b}$ & $22,9 \mathrm{a}$ & 0,0138 \\
& $\pm 0,25$ & $\pm 0,25$ & $\pm 0,25$ & \\
Altura do dossel no dia de avaliação do $_{\text {deslocamento }^{6}}$ & 17,60 & 17,20 & 17,20 & 0,8992 \\
Taxa de lotação $^{7}$ & $\pm 0,69$ & $\pm 0,69$ & $\pm 0,69$ & \\
& $1321,3 \mathrm{~b}$ & $1640,3 \mathrm{~b}$ & $1915,4 \mathrm{a}$ & $<0,0001$ \\
\hline
\end{tabular}

*Probabilidade; ${ }^{1}$ bezerras exclusivamente em pastejo de azevém; ${ }^{2}$ bezerras em pastejo de azevém recebendo $0,5 \%$ PC de farelo de arroz; ${ }^{3}$ bezerras em pastejo de azevém recebendo $1,0 \%$ PC de farelo de arroz; ${ }^{4} \mathrm{~kg} \mathrm{ha}{ }^{-1} \mathrm{MS} ;{ }^{5} \mathrm{~kg} \mathrm{MS}$ $100 \mathrm{~kg}^{-1} \mathrm{PC} ;{ }^{6} \mathrm{~cm} ;{ }^{7} \mathrm{~kg} \mathrm{ha}^{-1} \mathrm{PC}$.

Não houve interação entre os níveis de suplemento $\times$ ciclos de pastejo para as variáveis densidade volumétrica de lâmina foliar, colmo e material morto nos estratos de $0-10 \mathrm{~cm}$ e 10 $20 \mathrm{~cm}(\mathrm{P}>0,05)$. As densidades volumétricas de lâmina foliar $\left(2,71 \mathrm{~g} \mathrm{~cm}^{-3}\right)$ e colmo $\left(3,99 \mathrm{~g} \mathrm{~cm}^{-3}\right)$ no estrato de $0-10 \mathrm{~cm}$ foram semelhantes, independentemente do nível de suplemento fornecido (Tab. 3). A densidade volumétrica de material morto $\left(5,40 \mathrm{~g} \mathrm{~cm}^{-3}\right)$, no estrato de 0 $10 \mathrm{~cm}$, foi semelhante nos piquetes em que as bezerras foram mantidas exclusivamente em pastejo e em que receberam $0,5 \%$ PC de suplemento, e essa foi $46,3 \%$ maior quando comparada ao piquete em que as bezerras receberam $1,0 \%$ PC de farelo de arroz. A densidade volumétrica de lâmina foliar $(2,06 \mathrm{~g}$ $\left.\mathrm{cm}^{-3}\right)$, colmo $\left(1,10 \mathrm{~g} \mathrm{~cm}^{-3}\right)$ e material morto $\left(0,35 \mathrm{~g} \mathrm{~cm}^{-3}\right)$ no estrato de $10-20 \mathrm{~cm}$ foi semelhante independentemente do nível de suplemento fornecido. A similaridade na densidade volumétrica dos componentes estruturais do pasto nos estratos avaliados demonstra que os animais foram submetidos a estruturas de dossel semelhantes para seleção da forragem.

Tabela 3. Densidade volumétrica dos componentes estruturais do azevém nos estratos de 0-10 e 10-20 cm quando pastejado por bezerras de corte recebendo diferentes níveis de farelo de arroz

\begin{tabular}{|c|c|c|c|c|}
\hline \multirow{3}{*}{ Variável } & \multicolumn{3}{|c|}{ Níveis de suplemento (\% PC) } & \multirow{2}{*}{$\mathrm{P}^{*}$} \\
\hline & $0,0^{1}$ & $0,5^{2}$ & $1,0^{3}$ & \\
\hline & \multicolumn{4}{|c|}{ Estrato de $0-10 \mathrm{~cm}$} \\
\hline Lâmina foliar ${ }^{4}$ & $2,91 \pm 0,24$ & $2,50 \pm 0,24$ & $2,72 \pm 0,24$ & 0,4973 \\
\hline Colmo $^{4}$ & $4,54 \pm 0,30$ & $3,76 \pm 0,30$ & $3,66 \pm 0,30$ & 0,1101 \\
\hline \multirow[t]{2}{*}{ Material morto ${ }^{4}$} & $5,33 \pm 0,44 \mathrm{a}$ & $5,48 \pm 0,44 \mathrm{a}$ & $3,69 \pm 0,44 \mathrm{~b}$ & 0,0173 \\
\hline & \multicolumn{4}{|c|}{ Estrato de $10-20 \mathrm{~cm}$} \\
\hline Lâmina toliar ${ }^{4}$ & $2,05 \pm 0,30$ & $1,76 \pm 0,30$ & $2,39 \pm 0,30$ & 0,3534 \\
\hline Colmo $^{4}$ & $1,14 \pm 0,22$ & $1,16 \pm 0,22$ & $1,02 \pm 0,22$ & 0,0832 \\
\hline Material morto $^{4}$ & $0,41 \pm 0,01$ & $0,40 \pm 0,01$ & $0,25 \pm 0,01$ & 0,4849 \\
\hline
\end{tabular}

*Probabilidade; ${ }^{1}$ bezerras exclusivamente em pastejo de azevém; ${ }^{2}$ bezerras em pastejo de azevém recebendo $0,5 \%$ PC de farelo de arroz; ${ }^{3}$ bezerras em pastejo de azevém recebendo $1,0 \%$ PC de farelo de arroz; ${ }^{4} \mathrm{gcm}^{-3}$ 
A relação lâmina foliar:colmo mudou conforme os ciclos de pastejo, com maior valor $(3,05)$ no primeiro ciclo, e esse foi 6,5 vezes maior quando comparado ao sexto ciclo $(0,47)$. É esperado que, com o avanço do estádio fenológico do pasto, ocorra diminuição da participação de lâminas foliares no dossel (Drescher et al., 2006). A densidade volumétrica de lâmina foliar no estrato $0-10 \mathrm{~cm}$ foi semelhante no primeiro, segundo e terceiro ciclos de pastejo $\left(3,51 \mathrm{~g} \mathrm{~cm}^{-3}\right)$, sendo $61,9 \%$ maior que no sexto ciclo de pastejo. No quarto e quinto ciclos, essa variável apresentou valor intermediário $\left(2,18 \mathrm{~g} \mathrm{~cm}^{-3}\right)$ aos demais (Tab. 4). A densidade volumétrica de colmo no estrato $0-10 \mathrm{~cm}$ foi semelhante no quarto e quinto ciclos de pastejo $\left(5,50 \mathrm{~g} \mathrm{~cm}^{-3}\right)$; essa variável foi $59,4 \%$ maior que no primeiro ciclo de pastejo. No segundo, terceiro e sexto ciclos, essa variável apresentou valor intermediário $\left(3,59 \mathrm{~g} \mathrm{~cm}^{-3}\right)$ aos demais ciclos. A densidade volumétrica de material morto, no estrato de $0-10 \mathrm{~cm}$, no quinto ciclo, foi 12,08 vezes maior que no primeiro ciclo de pastejo. A quantidade de lâminas foliares declina ao longo do período de ocupação, enquanto passam a predominar horizontes com elevada densidade de matéria seca de colmos e material senescente (Carvalho et al., 2009), os quais formam uma barreira para a formação do bocado (Drescher et al., 2006).

Tabela 4. Densidade volumétrica dos componentes estruturais do azevém nos estratos de 0-10 e 10-20 cm nos ciclos de pastejo

\begin{tabular}{|c|c|c|c|}
\hline \multirow[t]{2}{*}{ Ciclo de pastejo } & \multicolumn{3}{|c|}{ Estrato $0-10 \mathrm{~cm}$} \\
\hline & Lâmina foliar ${ }^{1}$ & Colmo $^{1}$ & Material morto $^{1}$ \\
\hline $10 / 07-30 / 07$ & $3,06 \pm 0,34 \mathrm{a}$ & $2,12 \pm 0,43 \mathrm{c}$ & $0,72 \pm 0,62 \mathrm{c}$ \\
\hline $30 / 07-19 / 08$ & $3,74 \pm 0,34 \mathrm{a}$ & $3,33 \pm 0,43 \mathrm{~b}$ & $3,83 \pm 0,62 \mathrm{~b}$ \\
\hline 19/08-08/09 & $3,75 \pm 0,34 \mathrm{a}$ & $3,69 \pm 0,43 \mathrm{~b}$ & $4,180 \pm 0,62 \mathrm{~b}$ \\
\hline 08/09-22/09 & $2,55 \pm 0,34 \mathrm{~b}$ & $5,94 \pm 0,43 \mathrm{a}$ & $7,92 \pm 0,62 \mathrm{ab}$ \\
\hline $22 / 09-07 / 10$ & $1,82 \pm 0,34 \mathrm{~b}$ & $5,06 \pm 0,43 \mathrm{a}$ & $8,46 \pm 0,62 \mathrm{a}$ \\
\hline $07 / 10-22 / 10$ & $1,34 \pm 0,34 \mathrm{c}$ & $3,76 \pm 0,43 b$ & $6,85 \pm 0,62 \mathrm{ab}$ \\
\hline \multirow[t]{3}{*}{$\mathrm{P}^{*}$} & 0,0003 & 0,0001 & $<0,0001$ \\
\hline & \multicolumn{3}{|c|}{ Estrato $10-20 \mathrm{~cm}$} \\
\hline & Lâmina foliar $^{1}$ & Colmo $^{1}$ & Material morto ${ }^{1}$ \\
\hline 10/07-30/07 & $3,35 \pm 0,43 \mathrm{a}$ & $0,55 \pm 0,31 \mathrm{~b}$ & $0,39 \pm 0,15 \mathrm{a}$ \\
\hline $30 / 07-19 / 08$ & $1,88 \pm 0,49 \mathrm{a}$ & $0,85 \pm 0,35 \mathrm{~b}$ & $0,30 \pm 0,17 \mathrm{a}$ \\
\hline 19/08-08/09 & $2,84 \pm 0,43 \mathrm{a}$ & $0,91 \pm 0,31 \mathrm{~b}$ & $0,38 \pm 0,15 \mathrm{a}$ \\
\hline 08/09-22/09 & $3,14 \pm 0,43 \mathrm{a}$ & $2,29 \pm 0,31 \mathrm{a}$ & $0,61 \pm 0,15 \mathrm{a}$ \\
\hline $22 / 09-07 / 10$ & $0,97 \pm 0,43 \mathrm{~b}$ & $1,73 \pm 0,31 \mathrm{a}$ & $0,47 \pm 0,15 \mathrm{a}$ \\
\hline $07 / 10-22 / 10$ & $0,16 \pm 0,55 \mathrm{~b}$ & $0,82 \pm 0,38 \mathrm{~b}$ & $0,48 \pm 0,19 \mathrm{a}$ \\
\hline $\mathrm{P} *$ & 0,0007 & 0,0029 & 0,2167 \\
\hline
\end{tabular}

*Probabilidade; ${ }^{1} \mathrm{~g} \mathrm{~cm}^{-3}$.

A densidade volumétrica de lâmina foliar no estrato $10-20 \mathrm{~cm}$ foi semelhante no primeiro, segundo, terceiro e quarto ciclos de pastejo $\left(2,80 \mathrm{~g} \mathrm{~cm}^{-3}\right)$, sendo cinco vezes maior que no quinto e sexto $\left(0,56 \mathrm{~g} \mathrm{~cm}^{-3}\right)$ ciclos de pastejo (Tab. 4). A densidade volumétrica de colmo no estrato $10-20 \mathrm{~cm}$ foi semelhante no quarto $\mathrm{e}$ quinto ciclos de pastejo $\left(2,01 \mathrm{~g} \mathrm{~cm}^{-3}\right)$, e essa variável foi 2,6 vezes maior que nos demais ciclos avaliados $\left(0,77 \mathrm{~g} \mathrm{~cm}^{-3}\right)$. A densidade volumétrica de colmo no estrato $10-20 \mathrm{~cm}$ foi semelhante $\left(0,44 \mathrm{~g} \mathrm{~cm}^{-3}\right)$, independentemente do ciclo de pastejo.

Não houve interação $(\mathrm{P}>0,05)$ entre os níveis de suplemento $\times$ ciclos de pastejo para as variáveis: tempo por estação alimentar, número de passos entre estações alimentares e número de bocados em cada estação alimentar. As bezerras permaneceram semelhante tempo em cada estação alimentar $(9,4 \mathrm{~s})$ quando mantidas exclusivamente a pasto e recebendo $1,0 \% \mathrm{PC}$ de suplemento (Tab. 5). 
Tabela 5. Tempo e bocados por estação alimentar e número de passos entre estações alimentares de bezerras em pastejo de azevém recebendo níveis de suplemento energético

\begin{tabular}{lccc}
\hline Níveis de suplemento (\% PC) & Tempo/estação $^{4}$ & Passos/estação & Bocados/estação \\
\hline $0,0^{1}$ & $9,4 \pm 0,29 \mathrm{~b}$ & $1,68 \pm 0,055$ & $6,7 \pm 0,36$ \\
$0,5^{2}$ & $10,4 \pm 0,29 \mathrm{a}$ & $1,66 \pm 0,055$ & $7,3 \pm 0,36$ \\
$1,0^{3}$ & $9,4 \pm 0,30 \mathrm{~b}$ & $1,68 \pm 0,57$ & $7,1 \pm 0,34$ \\
$\mathrm{P}^{*}$ & 0,0198 & 0,9698 & 0,4059 \\
\hline
\end{tabular}

*Probabilidade; ${ }^{1}$ bezerras exclusivamente em pastejo de azevém; ${ }^{2}$ bezerras em pastejo de azevém recebendo $0,5 \%$ PC de farelo de arroz; ${ }^{3}$ bezerras em pastejo de azevém recebendo $1,0 \%$ PC de farelo de arroz; ${ }^{4}$ segundos.

As bezerras que receberam $0,5 \%$ PC de suplemento permanecem $10,6 \%(1 \mathrm{~s})$ a mais na estação alimentar quando comparadas às bezerras nos demais níveis. Conforme Carvalho et al. (2013), esse resultado caracteriza maior seletividade dessas bezerras quando comparadas às demais. $\mathrm{O}$ tempo em cada estação alimentar das bezerras suplementadas com nível de $0,5 \%$ PC foi influenciado pela densidade volumétrica de lâminas foliares no estrato $10-20 \mathrm{~cm}$ (FOL2), conforme a equação: $\hat{\mathrm{Y}}=8,01+1,19 \mathrm{FOL} 2$; $\mathrm{r}^{2}=0,54 ; \mathrm{P}=0,0152$. Com o aumento de $01 \mathrm{~g} \mathrm{~cm}^{-3}$ na densidade volumétrica de lâminas foliares no estrato de $10-20 \mathrm{~cm}$, espera-se que as bezerras que recebem $0,5 \%$ PC de farelo de arroz permaneçam $1,19 \mathrm{~s}$ a mais em cada estação alimentar. $\mathrm{O}$ fornecimento de $0,5 \% \mathrm{PC}$ de farelo de arroz tornou essas bezerras mais seletivas, buscando por lâminas foliares no dossel, as quais apresentam maiores teores de proteína bruta e digestibilidade. Esse resultado ratifica a importância dessa variável, no sentido de influenciar a permanência dos animais na estação alimentar (Prache e Rouguet, 1996).

Para as bezerras que receberam $1,0 \%$ PC de farelo de arroz, o tempo em cada estação alimentar está associado com a oferta de forragem $(r=0,55 ; \mathrm{P}=0,0646)$. A menor oferta de forragem para essas bezerras pode estar associada ao menor tempo de permanência na estação alimentar quando comparadas às bezerras que receberam $0,5 \%$ PC de farelo de arroz. Carvalho e Moraes (2005) também evidenciaram a relação existente entre o tempo de permanência na estação alimentar e a oferta de forragem. Quando é fornecido suplemento acima de $0,75 \%$ do PC para animais em pastejo, espera-se que ocorra principalmente o efeito de substituição do consumo de forragem pelo suplemento (Horn e McCollun, 1987), o que permite incremento na taxa de lotação e, dessa forma, a oferta de forragem diminui. O menor tempo na estação alimentar também pode ser explicado pela maior taxa de lotação quando fornecido $1,0 \%$ PC de suplemento, pois a maior densidade de lotação gera presença de grande quantidade de fezes e urina, o que leva os animais a diminuírem o tempo na estação alimentar, na tentativa de otimizar o uso do tempo e do esforço na busca por alimento (Carvalho et al., 2009).

O número de passos entre estações alimentares (1,7 passos) e o número de bocados por estação alimentar (sete bocados) foram semelhantes, independentemente do nível de farelo de arroz fornecido. $\mathrm{O}$ número de passos entre estações alimentares reflete a massa de bocado colhida no último bocado da estação alimentar anterior e também demonstra a condição do pasto (Carvalho e Moraes, 2005), o que indica que o manejo do pasto foi adequado em todos os sistemas alimentares avaliados.

A ingestão de forragem em nível de estação alimentar é um importante indicativo da condição do pasto (Carvalho et al., 2013) e este está ligado à densidade de forragem no estrato pastejável (Oliveira Neto et al., 2013). Foi observado que as bezerras exclusivamente em pastejo removeram $25,8 \%(6,0 \mathrm{~cm})$ da altura do dossel pré-pastejo, as que receberam $0,5 \% \mathrm{PC}$ de farelo de arroz removeram $22,0 \%(4,9 \mathrm{~cm})$ e as que receberam $1,0 \%$ PC de farelo de arroz removeram $24,4 \%(5,6 \mathrm{~cm})$ da altura do dossel na entrada dos animais no piquete. Conforme Carvalho et al. (2009), a queda acentuada na seletividade por folhas, em pastejo rotativo, só ocorre a partir da remoção de $50-40 \%$ da altura inicial, quando ocorre a mudança do horizonte pastejável. De acordo com esses dados, os resultados obtidos indicam que as bezerras, independentemente do nível de suplemento 
fornecido até o dia da avaliação de comportamento ingestivo (terceiro dia de ocupação do piquete, nos ciclos 1,2 e 3 ; e segundo dia de ocupação do piquete, nos ciclos 4,5 e 6), não mudaram o estrato de pastejo. Isso explica a semelhança no número de bocados em cada estação alimentar, independentemente do nível de suplemento fornecido.

As bezerras modificam o tempo de permanência em cada estação alimentar e seu deslocamento conforme os ciclos de pastejo. No primeiro ciclo, as bezerras permaneceram $22,2 \%(2 \mathrm{~s})$ a mais em cada estação alimentar quando comparado ao sexto (Tab. 6). Quando a disponibilidade de foragem de qualidade é alta, representada pela relação lâmina foliar:colmo, o que ocorre no primeiro ciclo de pastejo, os animais colhem bocados com maior massa, e isso possibilita que esses caminhem mais entre cada estação alimentar e permaneçam mais tempo em cada uma (Carvalho et al., 2013). A permanência dos animais na estação alimentar está ligada à quantidade presente de folhas (Prache e Rouguet, 1996). Além disso, os animais deslocam-se com o objetivo de aumentar a taxa de encontro com bocados potenciais, mudando suas estratégias de procura diária por forragem com o intuito de manter níveis adequados de consumo (Sichonany et al., 2015), o que explica a mudança no deslocamento conforme os ciclos de pastejo avaliados. No sexto ciclo de pastejo (final de outubro), as bezerras diminuíram o tempo na estação alimentar e aumentaram o deslocamento entre estação alimentar, provavelmente em razão da mudança na facilidade de apreensão da forragem, pois a depleção de recursos faz com que os animais aumentem o deslocamento entre estações alimentares (Roguet et al., 1998).

Tabela 6. Tempo e bocados por estação alimentar e número de passos entre estação alimentar de bezerras nos ciclos de pastejo

\begin{tabular}{lccc}
\hline $\begin{array}{l}\text { Datas de } \\
\text { avaliação }\end{array}$ & Tempo/estação $^{1}$ & Passos/estação & Bocados/estação \\
\hline $28 / 07$ & $11,0 \pm 0,41 \mathrm{a}$ & $1,8 \pm 0,078 \mathrm{a}$ & $8,0 \pm 0,47 \mathrm{a}$ \\
$17 / 08$ & $8,8 \pm 0,43 \mathrm{~cd}$ & $1,6 \pm 0,083 \mathrm{bc}$ & $6,8 \pm 0,37 \mathrm{~b}$ \\
$05 / 09$ & $10,2 \pm 0,41 \mathrm{ab}$ & $1,5 \pm 0,078 \mathrm{c}$ & $7,1 \pm 0,37 \mathrm{a}$ \\
$21 / 09$ & $10,5 \pm 0,41 \mathrm{ab}$ & $1,7 \pm 0,078 \mathrm{ab}$ & $7,7 \pm 0,37 \mathrm{a}$ \\
$07 / 10$ & $9,9 \pm 0,41 \mathrm{bc}$ & $1,6 \pm 0,078 \mathrm{bc}$ & $7,1 \pm 0,37 \mathrm{a}$ \\
$21 / 10$ & $8,0 \pm 0,41 \mathrm{~d}$ & $1,8 \pm 0,078 \mathrm{a}$ & $5,6 \pm 0,37 \mathrm{c}$ \\
$\mathrm{P}^{*}$ & $<0,0001$ & 0,0090 & 0,0003 \\
\hline
\end{tabular}

*Probabilidade; ${ }^{1}$ segundos.

No primeiro, terceiro, quarto e quinto ciclos de pastejo, as bezerras realizaram semelhante número de bocados em cada estação alimentar (7,5 bocados; Tab. 6). Nesses ciclos de pastejo (julho a início de outubro), as bezerras realizaram $33,9 \%$ mais bocados que no sexto ciclo de pastejo. Essa variável associou-se positivamente com a relação lâmina foliar:colmo $(\mathrm{r}=0,43 ; \mathrm{P}=0,0103)$. O menor número de bocados na estação alimentar, no sexto ciclo de pastejo, pode ser explicado pela modificação da estrutura do pasto, o qual dificulta a colheita de folhas e faz com que o herbívoro diminua seu ritmo de pastejo (Carvalho et al., 2009). Isso se deve ao fato de que, à medida que ocorre depleção das lâminas foliares, chega um momento em que os animais irão despender mais tempo na procura por folhas verdes dentro de um dossel repleto de colmos e material morto, contexto que resulta em efetiva redução na taxa de bocados (Orr et al., 2004). Assim, mais movimentos de manipulação da forragem são necessários antes da realização de um novo bocado (Fonseca et al., 2013).

\section{CONCLUSÕES}

O tempo de permanência na estação alimentar é a única variável do comportamento ingestivo que é alterada quando bezerras de corte em pastejo de azevém recebem farelo de arroz como suplemento. Esse tempo de permanência para bezerras que consomem $0,5 \%$ PC de farelo de arroz é determinado pela presença de lâminas foliares no dossel. O deslocamento entre estações alimentares é inalterado quando as bezerras recebem farelo de arroz, independentemente do nível fornecido, e muda nos ciclos de pastejo. 


\section{REFERÊNCIA}

BAILEY, E.W.; PROVENZA, F.D. Mechanisms determining large-herbivore distribution. In: PRINS, H.T.T.; LANGEVELDE, F. (Eds.). Resource ecology: spatial and temporal dynamics of foraging. Dordrecht: Springer, 2008. p.7-28.

BREMM, C.; ROCHA, M.G.; RESTLE, J. et al. Efeito de níveis de suplementação sobre o comportamento ingestivo de bezerras em pastagem de aveia (Avena strigosa Schreb.) e azevém (Lolium multiflorum Lam.). Rev. Bras. Zootec., v.34, p.387397, 2005.

CARVALHO, P.C.F.; MORAES, A. Comportamento ingestivo de ruminantes: bases para o manejo sustentável do pasto. In: CECATO, U.; JOBIM, C.C. (Orgs.). Manejo sustentável em pastagem. Maringá: UEM, 2005. v.1, p.1-20.

CARVALHO, P.C.F.; TRINDADE, J.K.; BREMM, C. et al. Comportamento ingestivo de animais em pastejo. In: REIS, R.A.; BERNANDES, T.F.; SIQUEIRA, G.R. (Eds.). Forragicultura: ciência, tecnologia e gestão dos recursos forrageiros. Jaboticabal: [Brendel], 2013. p.525-545, cap.33.

CARVALHO, P.C.F.; TRINDADE, J.K.; SILVA, S.C. et al. Consumo de forragem por animais em pastejo: analogias e simulações em pastoreio rotativo. In: SIMPÓSIO SOBRE MANEJO DA PASTAGEM/INTENSIFICAÇÃO DE SISTEMAS DE PRODUÇÃO ANIMAL EM PASTOS. 25., 2009, Piracicaba, SP. Anais... Piracicaba: FEALQ, 2009. p.61-93.

CONFORTIN, A.C.C.; QUADROS, F.L.F.; ROCHA, M.G. et al. Morfogênese e estrutura de azevém anual submetido a três intensidade de pastejo. Acta Sci. Anim. Sci., v.32, p.385-391, 2010.

DRESCHER, M.; HEITKÖNIG, I.M.A.; RAATS, J.G.; PRINS, H.T. The role of grass stems as structural foraging deterrents and their effects on the foraging behavior of cattle. Appl. Anim. Behav. Sci., v.101, p.10-26, 2006.

ELOY, R.L.; ROCHA M.G.; PÖTTER, L. et al Consumo de forragem por novilhas de corte recebendo farelo de arroz com e sem ionóforo. Ciênc. Rural, v.44, p.1223-1228, 2014.

FONSECA, L.; CARVALHO, P.C.F.; MEZZALIRA, J.C. et al. Effect of sward surface height and level of herbage depletion on bite features of cattle grazing Sorghum bicolor swards. J. Anim. Sci., v.91, p.4357$4365,2013$.

HORN, G.W.; McCOLLUN, F.T. Energy supplementation of grazing ruminants. In: GRAZING LIVESTOCK NUTRITION CONFERENCE, 1987, Jackson. Proceedings... Jackson: [s.n.], 1987. p.125136.
LACA, E.A.; UNGAR, E.D.; SELIGMAN, N. Effects of sward height and bulk density on bite dimensions of cattle grazing homogeneous sward. Grass Forage Sci., v.47, p.91-102, 1992.

OLIVEIRA NETO, R.A.; SILVA, J.H.S.; ROCHA, M.G. et al. Ingestive behavior, performance and forage intake by beef heifers on tropical pasture systems. Rev. Bras. Zootec., v.42, p.549-558, 2013.

ORR, R.J.; RUTTER, S.M.; YARROW, N.H. et al. Changes in ingestive behaviour of yearling dairy heifers due to changes in sward state during grazing down of rotationally stocked ryegrass or white clover pastures. Appl. Anim. Behav. Sci., v.87, p.205-222, 2004

PALHANO, A.L.; CARVALHO, P.C.F.; DITTRICH, J.R. et al. Padrões de deslocamento e procura por forragem de novilhas leiteiras em pastagem de capimmombaça. Rev. Bras. Zootec., v.35, p.2253-2259, 2006.

PÖTTER, L.; ROCHA, M.G.; ROSO, D. et al. Suplementação com concentrado para novilhas de corte mantidas em pastagens cultivadas de estação fria. Rev. Bras. Zootec., v.39, p.992-1001, 2010.

PRACHE, S.; ROGUET, C. Influence de la structure $d u$ couvert sur le comportement d'ingestion. Clermont-Ferrand: Institut National de la Recherche Agronomique, 1996. p.22-24.

ROGHET, C.; DUMONT, B.; PRACHE, S. Selection and use of feeding sites and feeding stations by herbivores: a review. Ann. Zootech., v.47, p.225-244, 1998.

ROMAN, J.; ROCHA, M.G.; PIRES, C.C. et al. Comportamento ingestivo e desempenho de ovinos em pastagem de azevém anual (Lolium multiflorum Lam.) com diferentes massas de forragem. Rev. Bras. Zootec., v.36, p.780-788, 2007.

SAS. Statistical Analysis System. SAS/STAT user guide, Version 9.2. Cary, NC: SAS Institute, 2009.

SICHONANY, M.J.O.; ROCHA, M.G.; PÖTTER, L. et al. Ingestive behavior of heifers in Alexandergrass pasture receiving different amounts of oat grain as supplement. Semin. Cienc. Agrar., v.36, p.2763-2774, 2015.

SICHONANY, M.J.O.; ROCHA, M.G.; PÖTTER, L. et al. Padrões de deslocamento de bezerras de corte que receberam suplementos isolipídicos em pastagem de azevém. Arq. Bras. Med. Vet. Zootec., v.66, p.818826, 2014.

SISTEMA Brasileiro de classificação de solos. Brasília: EMBRAPA, 2006. p.412. 